\title{
Ochi: praias privatizadas, resorts de luxo e a construção da visualidade jamaicana
}

\author{
Daniela Tavares Paoliello ${ }^{1}$
}

Resumo: No presente ensaio desenvolve-se uma reflexão sobre o ensaio fotográfico Ochi produzido em Ocho Rios, Jamaica. Com a privatização do litoral jamaicano e intensa exploração pela indústria turística, o que se constrói historicamente é uma visualidade excludente. Em Ochi a ordem visual é invertida e os nativos protagonizam as imagens.

Palavras -Chave: visualidade, turismo, jamaica, fotografia.

Ochi: private beaches, luxury resorts and the construction of Jamaican visuality

\begin{abstract}
In this essay, a reflection is developed on the construction of Ochi, a photographic essay produced in Ocho Rios, Jamaica. With the privatization of the Jamaican coastline and intense exploitation by the tourism industry, what is historically built is an excludent visuality. In Ochi the visual order is reversed and the natives protagonize the images.
\end{abstract}

Keywords: visuality, tourism, jamaica, photography.

No presente ensaio é feita uma reflexão em torno do ensaio fotográfico Ochi que produzi em 2017 no primeiro dia de férias de verão em Ocho Rios (Ochi), uma antiga vila de pescadores, situada no litoral norte da Jamaica, onde morei por três meses desenvolvendo minha pesquisa de doutorado. O conjunto de imagens apresentado e a discussão que segue pretende propor um retrato alternativo à recorrente construção do imaginário turístico jamaicano, na tentativa de tensionar a narrativa imagética que vem sendo historicamente produzida sobre a ilha.

\footnotetext{
${ }^{1}$ Daniela Paoliello é artista visual e faz doutorado no PPGARTES, UERJ. Foi contemplada com o XIII Prêmio Funarte Marc Ferrez de Fotografia em 2015. Em 2018 foi premiada como artista destaque do "Salão de Artes Novíssimos 2018" e em 2019 passou a integrar o acervo do Museu de Arte do Rio. Atualmente conduz uma pesquisa sobre as relações com a alteridade na fotografia a partir de trabalho de campo desenvolvido na Jamaica.
} 
A fotografia tem função central na construção do imaginário em torno do país e do regime de visualidade vigente, tendo sido utilizada desde o fim do século XIX para reforçar os intuitos de transformar a ilha em um grande "resort" e excluir cada vez mais os negros nativos do acesso às praias e demais espaços de convivência coletiva da cidade.

É nesse sentido que objetiva-se aqui analisar os elementos constituintes dessa visualidade excludente tensionando-a a partir da combinação entre análise histórica, relatos de campo e a apresentação do ensaio fotográfico realizado pela autora. Busca-se assim problematizar o regime de visibilidade estabelecido observando que as dinâmicas em torno de quem "aparece" e quem é eliminado desses espaços são determinantes nessa construção. Criar, portanto, um "espaço de aparição" a partir da fotografia, onde os corpos historicamente excluídos marcam sua presença na orla jamaicana, reforça uma dimensão política da fotografia e da imagem nos processos de reivindicação de espaços compartilhados da cidade de Ocho Rios.

O trabalho apresentado pretende, portanto, demonstrar como historicamente vem sendo construído - através da fotografia -, um regime de visibilidade excludente que não apenas contribui, mas que respalda as políticas de privatização das praias jamaicanas e reforça o caráter colonizador que a indústria turística exerce há mais de um século no país. Cafetinam a cultura e o território jamaicano, vendendo "experiências culturais" e atendendendo às demandas de uma globalização perversa.

Chego em Ocho Rios no dia 03 de abril e me instalo em Exchange, um pequeno bairro residencial em desenvolvimento localizado na parte alta da cidade, onde se encontram a maior parte dos bairros residenciais. Ochi é marcada por uma forte presença de símbolos americanos que disputam espaço com expressões tradicionais da cultura local, configurando um cenário sincrético. Grandes supermercados como o Progressive Foods dividem muros com os tradicionais mercados onde trabalham higglers e comerciantes rastafáris. O Jerk chicken feito ao ar livre nas churrasqueiras compete com o popular KFC e outros fastfoods das praças de alimentação que compõem os movimentados plazas. O som do reggae, do dancehall e o hip hop dos anos 2000 dominam as ruas através dos soundsystems que ocupam várias esquinas da cidade. Igrejas católicas, neopentecostais e o rastafarianismo constituem expressões religiosas 
características da ilha. Rasta, bless, uaguan são os principais comprimentos proferidos entre os passantes que misturam o inglês e a língua criola, o patois.

Com uma população constituída por 9.800 habitantes, Ocho Rios é o segundo destino mais turístico da ilha, sendo o que recebe o maior fluxo de cruzeiros de todo o litoral. Ochi é marcada por uma ostensiva presença da indústria turística, a orla é privatizada e tomada por resorts all inclusive 5 estrelas que detém trechos privados de praia para uso exclusivo dos hóspedes, caracterizando um turismo extrativista que se beneficia da força de trabalho local, mas não distribui seus lucros, apesar de ser um dos principais negócios do país.

A cidade é composta de um lado por montanhas cobertas de vegetação onde se configuram os principais bairros residenciais identificados no mapa abaixo como Content Garden e Great Pound. E de outro, por uma orla invisibilizada pelos muros de resorts all inclusive como o Sandals, Sand Castles, Rooms, entre outros.

$\mathrm{Na}$ imagem abaixo temos um mapa que exibe os pontos onde há hotéis na cidade e os valores de suas diárias que podem chegar a mais de 600 dólares. Além das dezenas de resorts, há ainda diversos condomínios fechados e luxuosos que também bloqueiam o acesso às praias e contam com suas praias privadas.

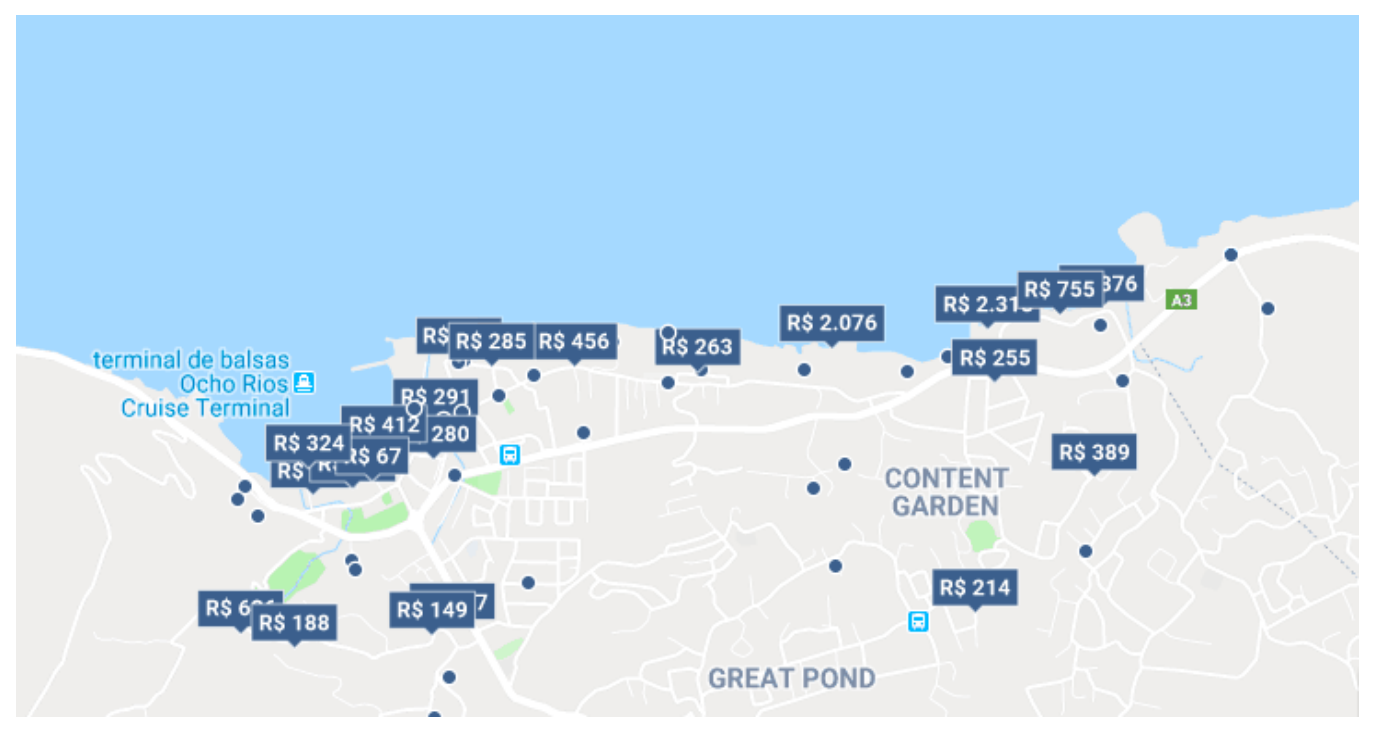

Imagem 1: Mapa de Ocho Rios com identificação dos hóteis e preços. Fonte: Google. 
Além das faixas de areia tomadas pelos resorts cinco estrelas onde nenhum não-hóspede pode entrar, as praias mais amplas e bonitas da ilha, sobretudo no litoral norte, foram vendidas ou emprestadas pelo governo jamaicano à investidores privados, que cobram altos valores de entrada, podendo chegar à 30 dólares norte-americanos, o que equivaleria hoje à 3 mil dólares jamaicanos. Vale pontuar que a venda das praias e a política de controle do uso que proíbe o acesso da orla a não-pagantes ou não-hóspedes, foi instaurada em 1956 a partir do Beach Control Act. A lei tem um caráter fortemente excludente e elitista, uma vez que esses valores representam quantias altíssimas se considerarmos o reduzido poder aquisitivo de maior parte da população jamaicana, sendo um salário mínimo equivalente a algo em torno de 6 mil dólares jamaicanos. O Beach Control Act afeta também a economia local, uma vez que atinge diretamente os pescadores dependentes do acesso ao mar para obter seu sustento. Políticas como essa não se restringem ao litoral, atingindo também os principais rios e cachoeiras da ilha que tem o acesso controlado.

Próximo à região do porto de cruzeiros à esquerda do mapa, observamos ainda um pequeno circuito de bares e restaurantes caros que vendem comida tradicional jamaicana, um plazza de lojas de diamante - House of Diamonds, o Taj Mahal Shopping Center com diversas lojas de souvenir, e um complexo chamado Island Village constituído de cafés, um cinema, boutiques, e um bar molhado com uma pequena piscina gratuita à beira do mar. Esse complexo de entretenimento, totalmente destoante do resto da cidade, destina-se sobretudo aos turistas de cruzeiro que passam apenas o dia na cidade e não se aventuram a circular fora desse circuito.

O que ronda o imaginário desses turistas, em sua maioria ingleses, canadenses e norteamericanos, parece ser o constante medo de encontrar o nativo sem mediação, fora dos espaços controlados onde os jamaicanos figuram dentro de um cenário de estereótipos e cumprem a expectativa do nativo exótico, pacífico, alegre e servil. O medo que ronda parece ser o de lhes estilhaçarem o paraíso, onde o real é um excesso, e o Outro, como propõe Homi Bhabha, escancara sua própria existência e o ameaça de desmembramento. (BHABHA, 1988)

Até o final do século XIX a ilha era vista como um local que inspirava medo e desordem, composta por uma natureza selvagem e doenças tropicais. Sobretudo após a decadência do açúcar e a abolição da escravidão, imaginava-se uma ilha arruinada composta por uma 
população dispersa e pouco organizada, que não pagava aluguel, vivia em cabanas miseráveis, apoiando a vida na pobreza de inhames e bananas, utilizando-se do calabash (cabaça) para produzir utensílios domésticos. (THOMPSON, 2006)

No entanto, com o crescente interesse do governo britânico e de companhias americanas, como a United Fruit Company, em estabelecer uma indústria do turismo na ilha, foi feito um massivo trabalho a fim de reinventar sua imagem no imaginário norte-americano e britânico, e construir uma "Nova Jamaica". Kristha Thompson observa:

Despite the availability of preventive medicines for tropical disesases in the 1880s, tourism promoters had to dispel the fear of the islands, wich hauntes the imaginations of pontetial clienteles in Britain and North America. They had to radically transform the island's much maligned landscapes into spaces of touristic desire for British and North American traveling publics. (THOMPSON, 2006, p.4)

A fotografia vai cumprir um papel fundamental na reconstrução desse imaginário, consolidando aos poucos uma imagem que Thompson denomina como "picturesque tropical garden", dado que toda a fetichização da ilha recaia sobre a representação de zonas que apresentavam sinais de cultivo. A natureza era, portanto, sempre apresentada em sua forma domesticada, como no cenário organizado das plantations de coco e banana.

Centenas de sessões de projeção de fotos foram feitas na Inglaterra e nos EUA no início do século XX utilizando-se de lanternas mágicas, onde eram exibidas imagens que reforçavam a ideia de um ambiente edênico, pacífico, tropical, abundante em frutas.

Proponents of the tourism industry, however, had not only to see their landscapes with new eyes, but to convince would-be travelers to do the same, to recognize Jamaica as a landscape filled with the loveliest scenary in the world. (THOMPSON, 2006, p.32)

Os nativos, por sua vez, eram representados nos cartões-postais, fotografias e pinturas dos viajantes de forma servil e exotizada ou figurando em imagens onde não eram o foco principal, muitas vezes segurando exuberantes cachos de frutas que eram o motivo central da cena como nos cartões postais que vemos na imagem 2 produzida em 1907. Ou na imagem 3, onde turistas brancos posam durante um passeio em 1910, exibindo frutas tropicais, e o único homem negro figura ao fundo, à esquerda. 
Também aos poucos vai sendo construído um imaginário em que a Jamaica é vista como um grande resort onde há apenas sol, mar e areia (sun, sea and sand), e nenhum nativo à vista. Essa imagem começa a ser propagada a partir de um projeto de publicidade elaborado pelo Jamaica Tourist Authority, autoridade criada em 1910.

The mandate of the Authority was to compile and disseminate information on Jamaica as a tourist resort. To this end, it employed various methods to promote Jamaica, primarily as a sun, sea and sand winter-get-away destination. (STUPART, Copeland A. and SHIPLEY, Rober. 2012)

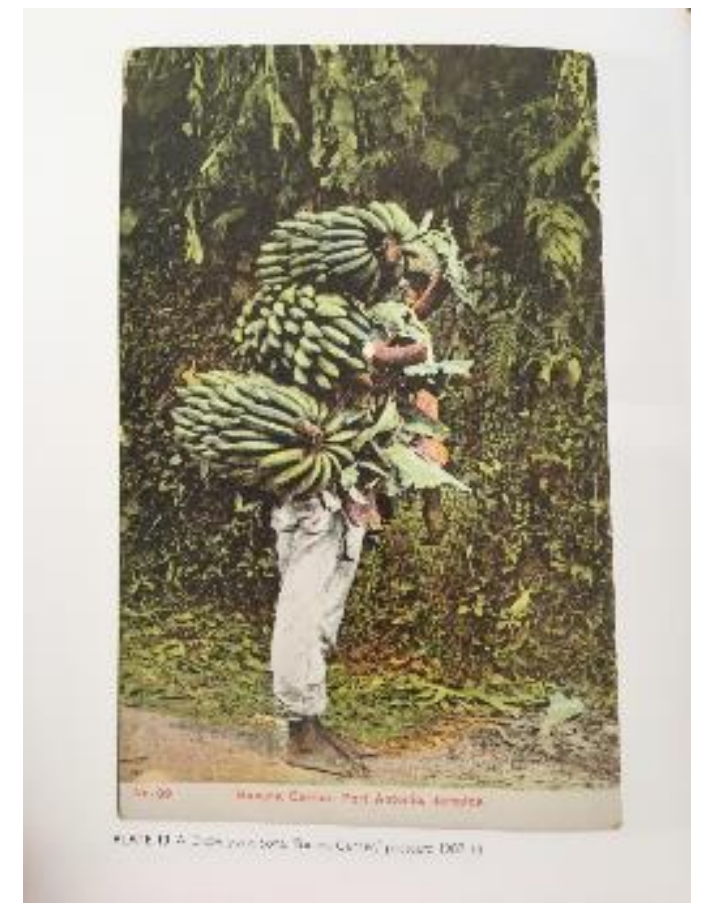

Imagem 2. S.d, fotografia, cartão-postal da Jamaica. Fonte: THOMPSON, 2006. 


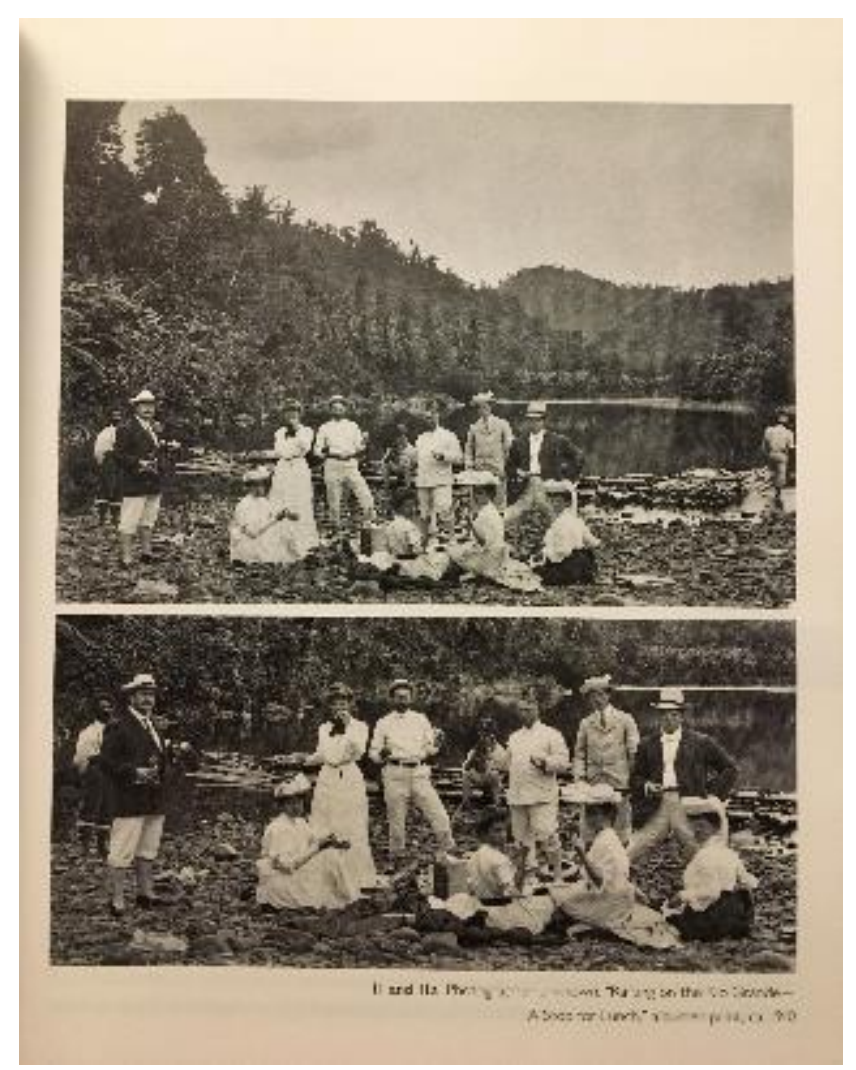

Imagem 3. S.d, fotografia. Fonte: THOMPSON, 2006.

Esse imaginário vigora até hoje e é, aliás, compartilhado por vários outros países da região caribenha que são vistos sob a mesma ótica a partir da qual a Jamaica parece ser um grande resort. Os corpos, quando aparecem nas narrativas mais recorrentes do país (em panfletos de turismo, cartões postais, ensaios fotográficos documentais) são o de turistas brancos desfrutando das belezas naturais, enquanto os negros nativos figuram sobretudo como guias, garçons, vendedores de frutas e artefatos turísticos ou de forma despersonalizada e geralmente, hiper-sexualizada como vemos na imagem 3, de um cartão-postal de 2000.

É interessante observar como o Beach Control Act impõe uma dinâmica de uso da praia que favorece a construção e materialização dessa imagem, excluindo os jamaicanos da orla. Previamente à implementação da lei, observa-se a existência - no conceituado hotel Myrtle Bank - de uma famosa piscina de água salgada à beira do mar, que parece ter servido como argumento ou modelo experimental para a privatização das praias, uma vez que a piscina era livre da potencial ameaça não só de animais marinhos, mas sobretudo livre de nativos: "Free of natural and human dangers of the beach, the Myrtle Bank's pool was like the beach but even 
better."(THOMPSON, 1993, p.22) Na mesma época, em Montego Bay, já iniciava-se uma discussão em torno da privatização de uma de suas praias mais bonitas do país, a Doctor's Cave Beach:

Precisely because of the beach was becoming such a central icon in Montego Bay's emergent touristic image, industry supporters submitted that the access to the beach should be controlled. Members of white elith bathing club, Doctor's cave Club, in particular, pointed to incidents in which black residents would bath nude in the sea as proof that the beach needed to be properly policed, managed, and regulated. (TAYLOR IN THOMPSON, 1993, p. 226)

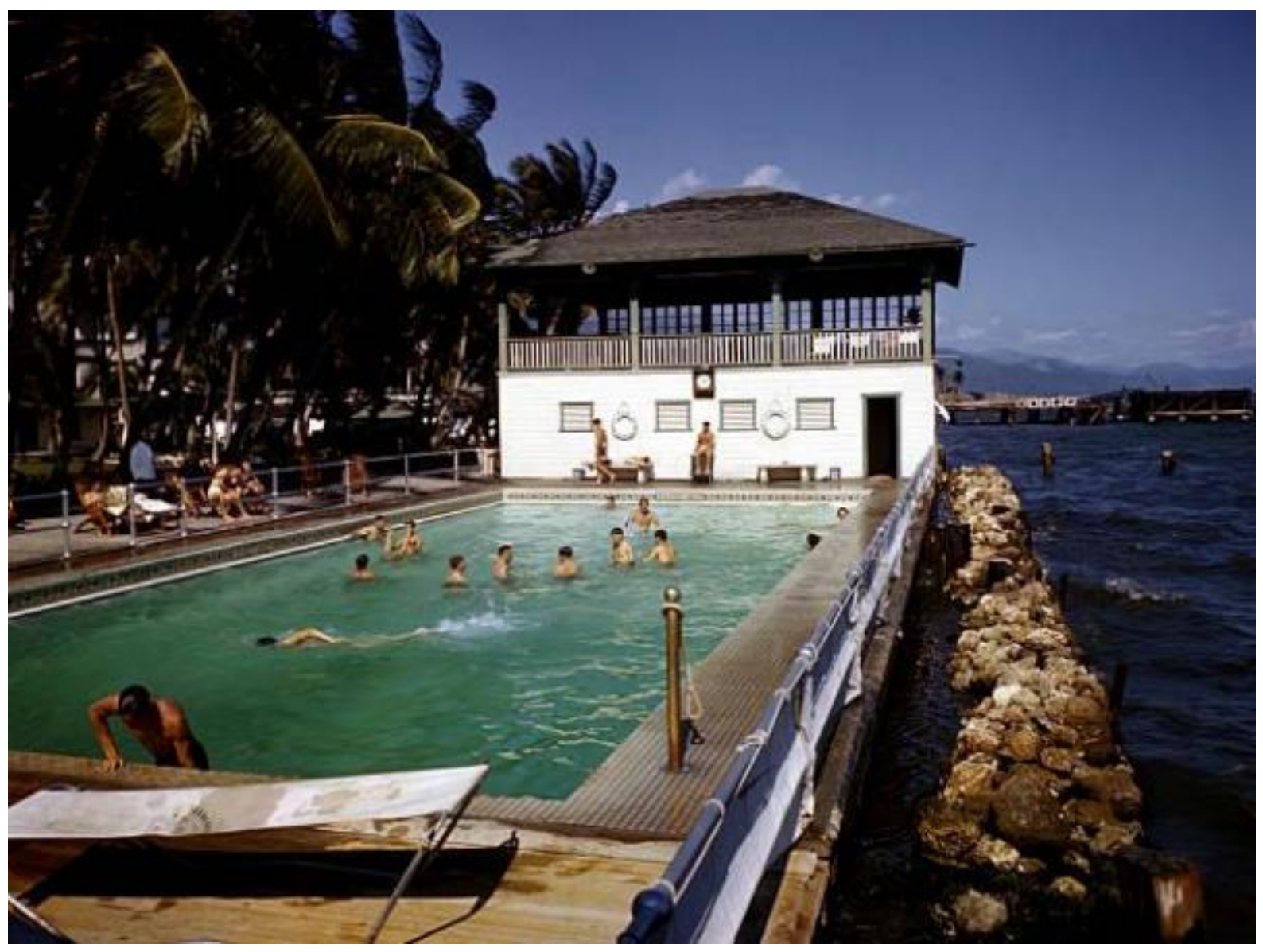

Imagem 4. S.d, piscina do hotel Myrtle Bank, Fotografia, Google, Acessado em 06/03/2018, s.d

Assim se dá nas últimas décadas o projeto - ainda em implementação - de privatização da orla, observando o olhar e o desejo dos turistas. A insatisfação dos jamaicanos com o turismo, o baixo envolvimento dos locais nos negócios e os conflitos entre turistas e nativos remonta o 
surgimento da indústria no início do século passado e permanece na atualidade. A declaração abaixo dada por um jamaicano em 1904 poderia certamente ter sido feita hoje, visto que as tentativas de exclusão dos nativos dos espaços públicos de lazer e a desigual distribuição dos lucros gerados pela indústria turística persiste.

Tourist! Cou yah sah! Dem is a confusion set of people. What we want dem for? - - - An what good dem going to do? All them idle buckra drive and ride over de mountains in dem buggy and harse wit all dem 'surance, and look down upon we poor naygurs. True dem say dey brings we money, but when time we eber see it? All de storekeepers dem in Kingston and the big tabern-keeper, dem is the one dat get the money out of dem.... An when de tourists come up to de country and see we working in de ground, dem is not goin' to do anything fa we, but take pitcha and laugh at we. Chu! Me bredder, only de buckra dem will profit. (TAYLOR, apud STUPART, 2012)

A Main Beach de Ocho Rios, praia principal da cidade, onde se localiza o porto de cruzeiros, é também regulada pelo Beach Control Act, fechada por grades e coordenada por seguranças. A mesma apresenta porém, um preço um pouco mais acessível se comparada às demais praias da região. Por cerca de 300 dólares jamaicanos, ou seja, algo em torno de 3 dólares americanos é possível acessar a praia, que tem seus horários de frequência limitados de $10 \mathrm{~h}$ às $18 \mathrm{~h}$. No entanto, ainda assim, o acesso é limitado, uma vez que, na ponta direita da orla se encontra um luxuoso resort cinco estrelas que tem seu trecho de praia privada, demarcado por bóias laranjas a partir das quais nenhum não-hóspede pode atravessar. Os vários corpos brancos estendidos nas espreguiçadeiras não ousam cruzar a demarcação. Apesar de terem livre acesso à toda extensão da praia, não o fazem, nem mesmo para uma caminhada.

Observa-se na construção da imagem da Jamaica o que Bhabha denomina de esteriótipo do nativo, pautado em uma dinâmica perceptiva que desliza entre as noções de barbárie e civilidade. Morando três meses na pequena Ocho Rios, pude perceber como os turistas não ultrapassam diversos limites territoriais imaginários: as bóias laranjas das praias, os portões do Island Village, o relógio da praça principal da cidade, assim como não entram nos restaurantes e bares locais, muito menos no mercado de frutas percebido como um dos lugares mais "perigosos da cidade". A maior parte dos turistas está sempre acompanhada de guias, sendo raro ver alguém se aventurar sozinho pelas ruas. 
O que temos, portanto, é um turismo que se desloca fechado em bolhas que atravessa a cidade sem estabelecer qualquer contato com o real, pois se sustenta de um consumo estereotipado e capitalizado da ilha e de seus corpos.

Usando o termo de Homi Bhabha poderíamos falar de uma "fixidez" que opera através de construções narrativas imagéticas e discursivas estereotipadas. Há uma ambivalência onde a alteridade é "ao mesmo tempo um objeto de desejo e escárnio", do fetiche e da fobia, abrindo "estrada para a fantasia colonial", que seria nada menos do que o "paraíso caribenho". É nesse sentido que Bhabha afirma: "o Outro estereotipado revela algo da fantasia (enquanto desejo, defesa) daquela posição de dominação(...)." (BHABHA, 1998, p.126) Reproduz-se, assim, a economia do prazer e do desejo conjuntamente com a economia do poder e da dominação. $\mathrm{O}$ turismo caribenho parece se sustentar justamente nessa lógica onde há um anseio em consumir a cultura jamaicana, e especialmente, a cultura Rastafari, experimentar a comida local e desfrutrar das belezas naturais ao som do reggae music, porém de forma pasteurizada e controlada, em espaços e dinâmicas nas quais o corpo negro torna-se palatável. O saldo dessa conveniência é obtido a partir da dominação, do controle e da exclusão dos corpos jamaicanos pela privatização de praias e rios, esmagando os pequenos negócios, numa tentativa brutal de sustentar o projeto da "Nova Jamaica" iniciado há mais de um século atrás.

Dia 01 de julho de 2017, depois de três meses morando na cidade, chego à Main Beach e a vejo, pela primeira vez, ocupada apenas por jamaicanos. Caixas de som, uma rede de vólei, jovens apostando corrida, o mar em êxtase. Nesse dia ao invés dos cruzeiros, diversos ônibus de excursão chegam de outras cidades trazendo grupos de diferentes regiões do país. Na variedade de pessoas que descem em Ochi, encontram-se grupos de famílias, mas principalmente jovens adolescentes em idade escolar. O spring break - férias de verão - altera as dinâmicas de uso dos espaços públicos da cidade, sobretudo das praias, cuja ocupação cotidiana no resto do ano é majoritariamente tomada pelo turismo. Nesse sentido, o spring break pode ser considerado um momento que tensiona as barreiras impostas pela indústria turística ao contrariar o objetivo principal das políticas restritivas de uso da praia: eliminar a presença dos nativos. 
O que se apresenta nessas imagens é uma praia ocupada por corpos negros, jamaicanos, sem uniformes, sem cores rastafari, sem frutas nas mãos, sem brancos no primeiro plano, como se vê nos cartões postais desde o século passado, nas imagens vendidas pelas agências de turismo, e em outras diversas representações visuais produzidas ainda hoje da ilha. Propõe-se aqui uma visualidade alternativa, contribuindo para a construção de um "espaço de aparição", em que corpos negros e nativos fazem parte do regime de visibilidade, e onde aparecer significa demandar o direito de existir e ocupar determinados territórios. O ensaio fotográfico apresentado e a discussão aqui desenvolvida pretendeu propor um retrato pós-colonial e alternativo à recorrente construção do imaginário turístico caribenho.

Considero importante pensar também para além do conteúdo da imagem, as discussões que o ensaio pode desencadear, trazendo à tona questões histórico-políticas relativas às dinâmicas de uso das praias jamaicanas na tentativa de tensionar a narrativa imagética que vem sendo historicamente produzida. A praia é jamaicana, nah mek dem win! (eles não vão vencer!).

Se, como afirma Hannah Arendt, "a aparência - aquilo que é visto e ouvido pelos outros e por nós mesmos - constitui a realidade" (ARENDT, 2007, p. 59), estar presente - exercendo nesse espaço seus códigos e se fazendo visível - pode ser pensado como uma forma de resistir e reivindicar sua inclusão. É portanto, necessário construir um novo regime de visibilidade, em que os negros jamaicanos façam parte da história visual que lhes concerne: "A presença de outros que veem, o vemos e ouvem o que ouvimos garantem-nos a realidade do mundo e de nós mesmos" (ARENDT, 2007, p. 60). Estar isolado da participação é estar distante do poder e das decisões. Se faz, portanto, essencial a ocupação desses espaços assim como a reconstrução da imagem que é produzida desses locais que, apesar de privatizados, estão ainda em disputa.

Um novo formato de colonização é reproduzido através da indústria turística e do consumo "cultural" agressivo que usurpa e distorce tudo aquilo que toca. Se é na ocupação do "lugar", onde, na perspectiva de Milton Santos (2005), reside a "única possibilidade de resistência aos processos perversos do mundo" pela sua potência de troca e construção política, a orla jamaicana figura nesse cenário como espaço central dessa luta. A praia é jamaicana, nah mek dem win! (eles não vão vencer!). 

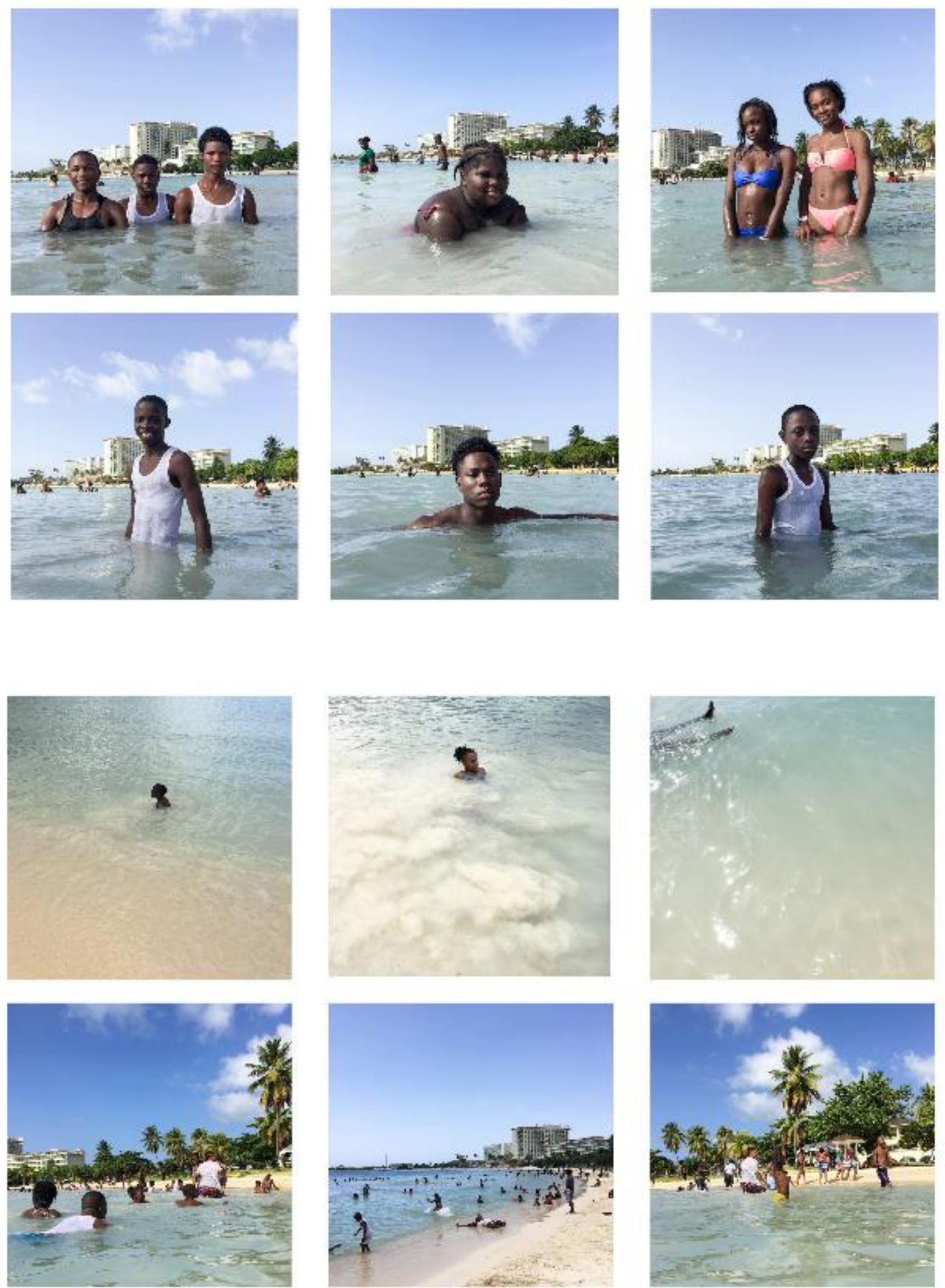

Imagem 5: A autora. Ochi. Fotografia. Dimensões variáveis. 


\section{Referências Bibliográficas}

BHABHA, Homi. O local da cultura. Belo Horizonte: Editora UFMG, 1998.

BARTH, Fredrik. A análise da cultura nas sociedades complexas. O guru, 2000.

FOUCAULT, Michel. O corpo utópico, as heterotopias. São Paulo: n-1 edições, 2013.

PONTY, M. Merleau. O visível e o invisível. São Paulo: Editora Perspectiva, 2003.

STUPART, Copeland A. and SHIPLEY, Robert. Jamaica's Tourism: sun, sea and sand to cultural heritage. Journal of Tourism Insights: Vol. 3: Iss. 1, Article 4, 2012

THOMPSON, Krista A. An eye for the tropics: Tourism, photography, and framing the Caribbean picturesque. Duke University Press, 2006. 